\title{
Rh sensitized pregnancy with high ICT titre with favourable foetal outcome: a rare case
}

\author{
Namrata Saxena $^{1}$, Manju Lal ${ }^{1}$, Navneet Kumar Bhat ${ }^{2}$, Mansi Sachdev ${ }^{1}$
}

\author{
${ }^{1}$ Department of Obstetrics \& Gynaecology, HIMS, Dehradun, Uttarakhand, India \\ ${ }^{2}$ Department of Paediatrics, HIMS, Dehradun, Uttarakhand, India
}

Received: 11 July 2015

Accepted: 14 August 2015

\section{*Correspondence:}

Dr. Namrata Saxena,

E-mail: msnamrata30@gmail.com

Copyright: (C) the author(s), publisher and licensee Medip Academy. This is an open-access article distributed under the terms of the Creative Commons Attribution Non-Commercial License, which permits unrestricted non-commercial use, distribution, and reproduction in any medium, provided the original work is properly cited.

\begin{abstract}
Leiomyosarcoma Rhesus (Rh) isoimmunization is the development of maternal IgG antibodies against fetal Rh Red Blood Cell (RBC) antigens. Transplacental passage of maternal Rh antibody (IgG anti-D) may result in Hemolytic Disease of the Newborn (HDN), a condition characterized by hemolysis, severe fetal anemia and generalized fetal edema (hydrops fetalis). The severity of Rh hemolytic disease may be assessed in the Immunized patient by several different means which include: past obstetric history, maternal antibody titer, ultrasonography, amniotic fluid bilirubin quantification, and percutaneous umbilical blood sampling. A past history of fetal demise, hydrops fetalis, intrauterine transfusion or neonatal exchange transfusion implies that the present pregnancy is or will be severely affected because Rh disease effects on the fetus generally recur or present progressively earlier or more severely with each successive $\mathrm{Rh}$ positive pregnancy. We present here a rare case of Rh sensitized pregnancy with high ICT titre who had normal fetal outcome.
\end{abstract}

Keywords: Rhesus $(\mathrm{Rh})$ isoimmunization, Favourable outcome, Indirect Coomb test (ICT)

\section{INTRODUCTION}

Haemolytic disease of the newborn, secondary to rhesus alloimmunisation was a major contributor to perinatal morbidity and mortality about 50 years back. Today, rhesus immune globulin has markedly decreased the prevalence of this disease so much that less than three cases occur in every 1000 live births. ${ }^{1} \quad \mathrm{Rh}$ alloimmunization occurs when maternal immune system is sensitized to $\mathrm{D}(\mathrm{Rh})$ erythrocyte surface antigen. The most common causes of maternal $\mathrm{Rh}$ alloimmunisation are blood transfusion and antepartum or intrapartum fetomaternal hemorrhage (abdominal trauma, abortion, ectopic pregnancy, invasive obstetric procedures, placental abruption and external cephalic version). The risk of alloimmunization is affected by several factors, including the degree of fetomaternal hemorrhage and maternal immune response. ${ }^{2}$ The blood grouping of both the parents is needed to be performed, along with Rh type and anti D antibodies (indirect Coombs test) at every antenatal visit as isoimmunised pregnancies are at an increased risk of developing foetal anaemia, hydrops and stillbirth. ${ }^{3}$ Here, we are presenting a rare case report in $\mathrm{Rh}$ sensitized pregnancy with high ICT titre who had normal fetal outcome.

\section{CASE REPORT}

A 22 year female, G3P2L1, at 35 wks 4 days gestation, was referred to HIHT on $9 / 5 / 14$ in view of Rh sensitized pregnancy with anemia and $\mathrm{h} / \mathrm{o}$ previous affected pregnancy. Her blood group was A negative while her husband blood group was A positive. She was referred with ICT titer as $3+$. The first delivery was 2 years back of a healthy male baby followed by $2^{\text {nd }}$ child birth 1 year back which was also FTND of a male baby who 
developed severe jaundice and underwent exchange transfusion for that and expired at 4 days of life. There was no history of anti D immunoglobulin administration in previous pregnancies.

At the time of presentation, her $\mathrm{Hb}$ was $6.38 \mathrm{gm} \%$ for which she was on oral iron therapy. She also had UTI .On examination, pallor was ++ , rest of the general systemic examination was within normal limits, PR - 98/min, BP $110 / 70 \mathrm{mmHg}$. Per abdominal examination revealed uterus size of 32-34 weeks, cephalic in LOA position, FHS was present and regular, uterus relaxed. Hb level was reassessed and was found to be 6.2. Ultrasound Obs and Doppler which showed SLIUF with GA 34WKS3 days, cephalic presentation, placenta was fundo anterior, liquor was adequate, no signs of isoimmunisation were seen. Doppler study was normal, MCA flow was normal, S/D 5.6, PSV 46.8. ICT titre was repeated after 48 hours $\&$ that was constant $(1: 2048)$.

This patient was treated for UTI with antibiotics and 3 units of PRBCs were transfused and was discharged satisfactory on oral iron therapy. She was under regular follow up on OPD basis till she reached at term. She was admitted electively at POG 37 week 2 days for termination of pregnancy. Her repeat $\mathrm{Hb}$ was found to be 8.67, Pediatric consultation was taken and prognosis was explained. Under close monitoring, induction of labour was done with dinoprostone gel followed by augmentation with syntocinon which was followed by FTND on $21 / 5 / 14$, an alive female baby was delivered by vertex with a birth weight of $2.125 \mathrm{~kg}$ (LBW), with good APGAR score (9/10/10), no gross congenital anomaly was seen, baby cried at birth, cord blood sample was collected and was sent for investigations ( $\mathrm{Hb}$, blood picture, DCT, T. bil, reticulocyte count, blood group, PCV). Baby was shifted to NICU. DCT was found to be POSITIVE, so IVIG was given to baby. Serum bilirubin of baby was in increasing trend so phototherapy was given. Baby's hemoglobin was low (13.59 gm\%), so 2 units of PRBC were transfused prophylactically. The general condition of the baby was stable and was accepting breast feed well so was shifted to mother side on PND 9. Immunization was done and mother and baby were discharged in satisfactory condition. Baby was followed up in pediatric OPD for regular check-up and was found to be healthy.

\section{DISCUSSION}

Rhesus (Rh) isoimmunization is the development of maternal IgG antibodies against fetal Rh Red Blood Cell (RBC) antigens. Blood production in the fetus begins at about $3^{\text {rd }}$ week and $\mathrm{Rh}$ antigen are seen as early as 38 days after conception. The initial response to D antigen is slow and may take 6 months to develop. However, reexposure to the antigen produces a rapid immunological response usually measured in days. The sensitized mother produces IgG anti-D (antibody) that crosses the placenta and coats D-positive fetal red cells which are destroyed in the fetal spleen. Mild to moderate hemolysis causes increased indirect bilirubin while severe hemolysis leads to red blood cell production by the spleen and liver. Subsequently, portal hypertension with placental edema interferes with placental perfusion and ascites develops. Hepatomegaly, increased placental thickness, and polyhydramnios often precede the development of hydrops (fetal heart failure). As liver damage progresses decreased albumin production results in the development of anasarca, and effusions. In the present case, the patient had a previous affected pregnancy and the male child died because of hydrops fetalis in spite of exchange transfusion.

Once Rh sensitisation occurs, rhesus immune globulin is no longer effective. Overall, $16 \%$ of $\mathrm{Rh}$-negative women will become sensitized after their first pregnancy if Anti$\mathrm{D}$ antibody is not given.

In general, women with titers higher than 1:4 should be considered Rh-alloimmunized. These are usually performed monthly until 24 weeks of gestation, after which, titer should be repeated every 2 wks. A critical titer is defined as the titer associated with a significant risk of fetal hydrops. Usually, pregnancy in which antibody titers are 1:8 or lower can be managed by serial monitoring of maternal antibody titers. On the contrary, if the titer is $1: 16$ or higher, fetal wellness is mandatory by ultrasonography to evaluation of Middle Cerebral Artery Peak Systolic Velocity (MCA-PSV) or serial amniocentesis for delta OD 450 if the former is not available. $^{4}$

In literature there is one case report of successful outcome in $\mathrm{Rh}$ sensitized pregnancy where female incidentally had bicornuate uterus.

Thus this is an unusual case where we could not explain the favourable outcome in this baby. But a good antenatal monitoring with good neonatal management had a definite role to some extent in this outcome. Administration of IV Ig may have played role in this case but further studies are required to substantiate this hypothesis.

\section{Funding: No funding sources Conflict of interest: None declared Ethical approval: Not required}

\section{REFERENCES}

1. McLean LK, Hedriana HL, Lanouette JM, Hanns C, Haesslein. A retrospective review of isoimmunised pregnancies managed by middle cerebral artery peak systolic velocity. Am J Obstet Gynecol. 2004;190:1732-8.

2. Cacciatore A, Rapiti S, Carrara S, Cavaliere A, Ermito S, Dinatale A, et al. Obstetric management in $\mathrm{Rh}$ alloimmunizated pregnancy. J Prenat Med. 2009;3(2):25-7. 
3. Bullock R1, Martin WL, Coomarasamy A, Kilby MD. Prediction of fetal anemia in pregnancies with red-cell alloimmunization: comparison of middle cerebral artery peak systolic velocity and amniotic fluid OD450. Ultrasound Obstet Gynecol. 2005;25(4):331-4.

4. Moise KJ Jr. Management of rhesus alloimmunization in pregnancy. Obstet Gynecol. 2002;100(3):600-11.
5. Acharya S, Ahmed S. A case of pregnancy with rhesus antibody and bicornuate uterus - a favourable outcome:a case report. Cases J. 2010;3:50.

Cite this article as: Saxena N, Lal M, Bhat NK, Sachdev M. Rh sensitized pregnancy with high ICT titre with favourable foetal outcome: a rare case. Int $\mathbf{J}$ Reprod Contracept Obstet Gynecol 2015;4:1574-6. 